\title{
TEACHING DISCOURSE ANALYSIS OF THE CATEGORY OF SUBJECT
}

\author{
Marina Fomina \\ Institute of Foreign Languages, Moscow City University (Russia)
}

\begin{abstract}
The paper focuses on the DA of the category of semantic subject and aims to introduce a step-by-step algorithm that can be applied for the analysis of Russian and English academic texts. Despite its status of being a well-established and viable research method, DA's framework to be introduced in the classroom and its teaching effect are still relatively under-researched.
\end{abstract}

Keywords: Discourse analysis, semantic subject, academic discourse, dialogue with the reader, academic writing skills.

\section{Introduction}

Recent years have witnessed a vivid interest in various applications of discourse analysis (DA) in the classroom environment (e.g. see (Cots, 1996), (Martínez, 2011), (Alsoraihi, 2019)). DA as a research method for studying language use in context is viewed as "a broad and fast-developing interdisciplinary field", an approach to "promote the application of critical thought to social situations" and to unveil the strategies employed within socially dominant discourses (Martínez, 2011). Researchers claim that DA can enhance the quality of teaching / learning techniques, serve as a powerful tool to develop professional and linguistic competencies. Despite its status of being a well-established and viable research method, DA's framework to be introduced in the classroom and its teaching effect are still relatively under-researched.

\section{Methodology}

Students are taught DA in their theoretical disciplines such as theory of grammar, lexicology, introduction to linguistics, general linguistics. At the beginning of the term students are offered research projects for teams of 3-5 students (see (Suleimanova, Yaremenko, \& Vodyanitskaya, 2018) for examples of actual research projects completed within PBL (project-based learning) format combined with role play in synergetic teaching). The projects help students develop relevant research skills and master a variety of research methods and techniques. Some of the projects rely on such a research tool as DA.

The paper focuses on the DA of the category of semantic subject and aims to introduce a step-by-step algorithm that can be applied for the analysis of Russian and English academic texts.

The analysis starts with collecting the empirical data for the research. The common strategies employed in academic discourse reveal themselves through textbooks, dissertations, lectures, monographs, etc. The research article (RA) "remains the pre-eminent genre of the academy" (Hyland, 2009) and is regarded as a most significant and common research tool to present the author's research and findings in the academic circle. RA abides by - as any other academic or literary genre - a set of rules and requirements, and has its own peculiarities. When submitting a paper, authors are to follow certain standards and guidelines, in terms of both the content and layout. Thus, the empirical base of the study can rest on a number of recent scientific articles on linguistics published in academic journals. Another genre students may set their sight on for the analysis is dissertation. Being significant and common research tools to present the author's research and findings in the academic circle, dissertations and research papers reproduce the academic's multistep cognitive activity: Purpose of Study / Problem Statement $\rightarrow$ Research Hypothesis $\rightarrow$ Proving the Hypothesis $\rightarrow$ Summary of Findings.

Then students turn to semantic and structural analyses accompanied by content analysis and an interpretation of their results. They focus on the linguistic means the speaker opts for to establish a dialogue with the reader and adopt an appropriate identity in academic texts - "stance and engagement" expressions (Hyland, 2005), with the focus on hedging and boosting devices as linguistic representations of the category of subject. While "stance" includes features which "refer to the ways writers present 
themselves and convey their judgments, opinions, and commitments", "engagement" is managed by writers in the ways they "relate to their readers with respect to the positions advanced in the text" (Hyland, 2005). These two functions are realized by the following "key resources of academic interaction": "stance" expressions - hedges, boosters, attitude markers, self-mentions; "engagement" expressions - reader pronouns (you, your and inclusive we); directives (that "instruct the reader to perform an action or to see things in a way determined by the writer"); appeals to shared knowledge ("the presence of explicit markers where readers are asked to recognize something as familiar or accepted"); personal asides (that "allow writers to address readers directly by briefly interrupting the argument to offer a comment on what has been said"); questions (the strategy to involve the reader by "inviting engagement and bringing the interlocutor into an arena where they can be led to the writer's viewpoint" (Hyland, 2005).

To collect the data (stance and engagement expressions in our case) within content analysis "manually" (search options in Microsoft Word for .rtf or .doc(x) formats or Adobe Reader / PDF-Xchange Viewer for pdf files might be of some help still do not provide for the scenario - a frame of the text analysis) turns out to be a multi-hour monotonous and tedious task. What can significantly facilitate the research procedure and reshape research methodology is digital tools. Consider a free desktop search engine and semantic analysis software from Acetic / Semantic-Knowledge - Tropes Zoom. Uses of Tropes software (now available in English, French, Spanish, Portuguese, Romanian) cover a wide spectrum ranging from content-analysis and defining stylistic register, chronology, communicators, parts of speech (frequency), key episodes, logical steps, modality, etc. to analysis of free-response questionnaires, studies of the effectiveness of advertising, monitoring changes to brand image, analysis of clinical interviews, behavioral studies, or analysis of literary works (http://www.semantic-knowledge.com/). After being introduced to the basic features of the system, students are encouraged to support the research procedure with the software - e.g. all the statements with reader pronouns (you, your and inclusive we) as well as absolute and relative frequency of these "engagement" expressions can be easily extracted from the analysed text in no time.

\section{Results}

Now consider the DA's framework, the empirical data collected as well as the results of content, semantic and structural analyses of the data.

\subsection{Empirical data}

The empirical data for the research can be collected from Russian and English academic texts. Some of the research projects initiated by the Chair of Linguistics and Translation Studies (Moscow City University) and completed in 2018-2019 academic year relied on recent $\mathrm{PhD}$ dissertations in linguistics, while other teams analysed dissertation summaries, or scientific articles on linguistics published in Russian- and English-language academic journals.

In the paper, let us consider some of the results obtained within a research project on Russian parenthetical words / clauses (e.g. Думается, ... - lit. Think-refl.; Как можно заключить, ... - lit. As may conclude-inf.; Как представляется, ... - lit. As appear-refl.) to illustrate professional competencies and skills mastered by students through working on the project. The data of the study have been collected from ten $\mathrm{PhD}$ dissertations in linguistics defended for the period 2014-2018. To illustrate the methods and techniques employed as well as some of the research results, consider two PhD dissertations (Evteeva, 2014; Tivyaeva, 2018).

\subsection{Semantic and structural analysis of Russian boosters and hedges}

Research findings show that the extent to which authors can reveal their identity and make their voices pronounced varies and appears to be culture- and language-specific. Whereas authors of English academic texts opt for stronger identity (e.g. by means of author pronouns $I, m e, m y$ ), Russian academic texts demonstrate the avoidance of specific reference to the author by eliminating the use of first person pronouns. Instead, they use impersonal structures allegedly designed to disguise the author and to focus on factual information; first person plural pronoun $\mathrm{Mbl}$ ('we') to indicate solidarity with the academic world; parenthetical words and clauses (that feature definite-personal or impersonal structures) and some other linguistic means.

In the paper, let us consider some of the results obtained within a research project on Russian parenthetical words / clauses (e.g. Думается, ... - lit. Think-refl.; Как можно заключить, ... lit. As may conclude-inf.; Как представляется, ... - lit. As appear-refl.) to illustrate professional competencies and skills mastered by students through working on the project. 
Russian parenthetical words / clauses such as по-видимому ('apparently'), по всей видимости ('apparently / to all appearance'), Как представляется, ... (lit. As appear-refl. - 'It appears (that) / It seems (that) ...'), кажется (lit. seem-refl. - 'it seems (that)'), по некоторым признакам ('from certain indications / characteristics / by certain signs / symptoms'), Как можно заключить, ... (lit. As таy conclude-inf. - 'You might take it that ...'), Как видно, ... (lit. As seen - 'Apparently / Clearly / Obviously ...'), судя по всему (lit. judging by all - 'to all appearance'), Надо полагать, ... (lit. Must suppose-inf. - 'I think / I guess'), Думается, ... (lit. Think-refl. - 'I think (that) ...'), etc. mark the writer's judgements, feelings, or viewpoint about something. According to the model of interaction in academic discourse offered by K. Hyland, these models relate to hedges as they "indicate the writer's decision to withhold complete commitment to a proposition, allowing information to be presented as an opinion rather than accredited fact" (Hyland, 2005). Hedged propositions allow writers to express their "uncertainty concerning the factuality of their statements or to indicate deference to their readers" (Hyland, 1994) - cf. the following epistemic devices that convey the information about the author's perspective:

It seems that, at this step, there are interesting collaborations between secondary teachers, which greatly facilitates the integration of several school subjects into interdisciplinary projects (Carmo, 2018);

... we may conclude that the nature of foreign language learning in the current era of social networks appears to be to a large extent influenced by referring to some new roles of social media users ... (Carmo, 2018);

On the contrary, the low groups of students would not presumably learn the vocabulary from testing themselves with vocabulary worksheet or even creating a storyline with new words (Carmo, 2018).

Boosters "help writers to present their work with assurance while effecting interpersonal solidarity" (Hyland, 1999). Boosting devices allow authors to "express their certainty in what they say and to mark involvement with the topic and solidarity with their audience", "they function to stress shared information, group membership, and engagement with readers" (Hyland, 1999), cf::

The validity of the figures obtained obviously depends on the quality of the databases used and their representativeness (Carmo, 2018);

Although some ingredients are surely common, others are specific to one recipe and not the other (Carmo, 2018).

Cf. the following examples of Russian parenthetical clauses that convey this information: Hado сказать, ... (lit. Must say-inf. - 'It must be said / Actually ...'), Следует oтметить, ... ('It should be noted ...'), Необходимо подчеркнуть, ... ('It should be emphasized ...'), Нельзя не сказать о том, что ... ('It must be said that ...'); Важно отметить, что ... ('It was / is significant to note that ...'); Достаточно сказать, что ... ('Suffice it to say that ...'); Как хотелось бы отметить, ... (lit. As want-refl. subj. note-inf. - 'I would like to note that ...'); Важно отметить, что ... / Следует подчеркнуть, что ... ('It was / is significant to note that ... / Notably, ...'), etc. typology:

Syntax-wise, the collected data was then split up into the clusters relying on the following

1) parenthetical main clauses (definite-personal clauses - cf. Полагаю ('I suрроsе') / Считаю / Думаю ('I think / I believe') / Напомню ('I would like to remind (the reader)') / Напомним, ... ('We would like to remind (the reader) that ...'); impersonal clauses with impersonal reflexive verb cf. Представляется ('It арреагs (that) / It seems (that)') / Думается ('I think (that)') / Кажется, ... ('It seems (that)'); impersonal clauses with modal words - cf. Надо полагать ((lit. Must suppose-inf. 'I think / I guess') / Надо сказать (lit. Must say-inf. - 'It must be said / actually') / Следует полагать ('It should be assumed (that) / Presumably') / (Причем) следует отметить ('It should be noted') / (Причем) следует подчеркнуть ('It should be stressed / noted / emphasized') / Необходимо подчеркнуть ('It should be етрhasized') / Нельзя не сказать о том ('It must be said that') / Можно предполагать, ... ('One can assume'); impersonal clauses that denote measure / degree / evaluation with predicative words ending with -o and with / without infinitive - cf. Достаточно сказать ('Suffice it to say (that)') / Интересно (отметить / mo) ('It is interesting (to note) that') / Важно (отметить / mo), что ... ('It was / is significant to note that ...') / Возможно ('Perhaps') / Ecтественно ('Naturally') / Очевидно, что ... ('Apparently / Obviously / Evidently / It is obvious / evident that ...'));

2) parenthetical subordinate clauses (subordinate clauses - cf. Как я считаю, ... (lit. As I think'I believe ...'); subordinate impersonal clauses - Как (нам) представляется (lit. As (us) appear-refl. 'It appears (that) / It seems (that)')/ видно (lit. As seen - 'Apparently / Clearly / Obviously') / можно заключить (lit. As may conclude-inf. - 'You might take it that') / хотелось бы отметить (lit. As want-refl., subj. note-inf. - 'I would like to note that') / (нам) кажется, ... (lit. As seem-refl. - 'It seems (that) ...'); 
3) parenthetical words / parenthetical phrases - cf. По всей видимости ('Apparently / To all appearance') / Судя по всему ('To all appearance') / По некоторым признакам ('From certain indications / characteristics / By certain signs / symptoms') / На наш взгляд, ... ('In оит opinion ...') (Fomina, 2017).

Consider some of the research results obtained by the research team. The following table represents the results of content analysis - absolute and relative frequency of Russian parenthetical words / clauses that function as boosters and hedges.

Table 1. Absolute and relative frequency of Russian parenthetical words / clauses.

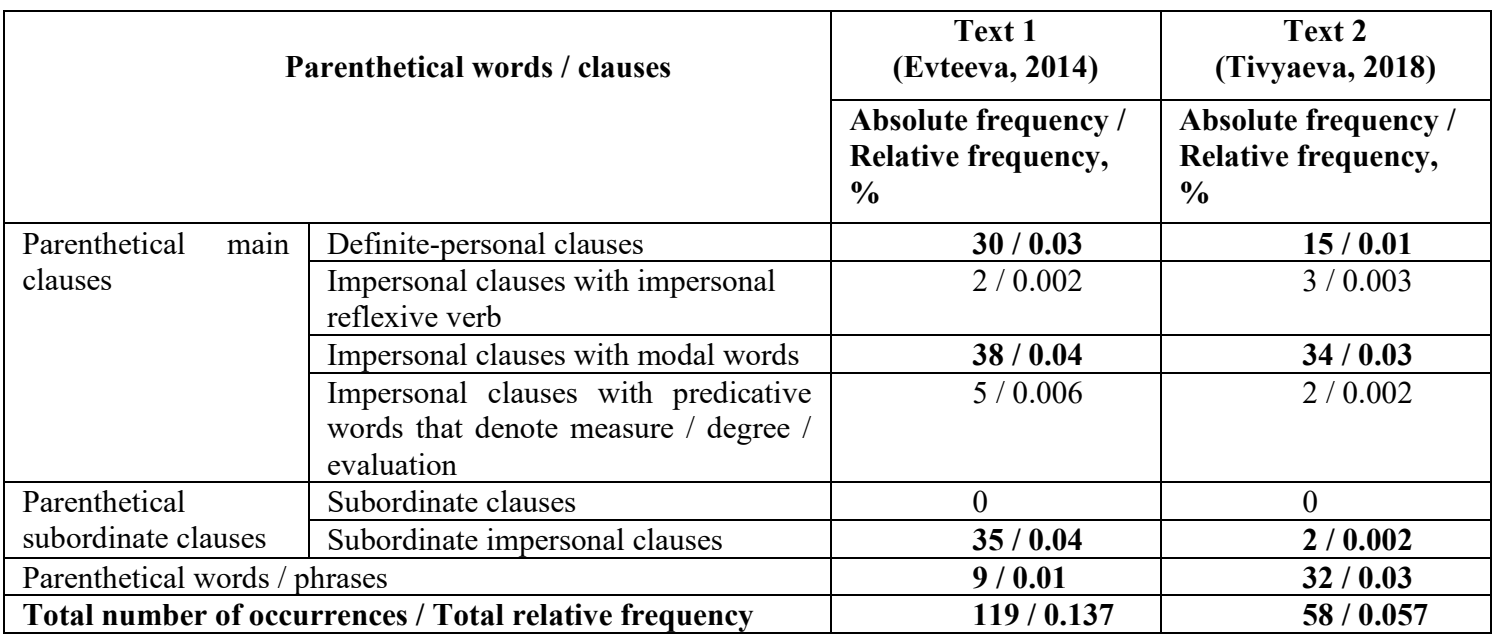

The content analysis performed by the team revealed that both texts feature frequent impersonal structures and forms of first person plural pronoun $\mathrm{Mbl}$ ('we') employed by the authors to indicate solidarity with the academic world, cf.:

Необходимо подчеркнуть, что, несмотря на предположительное наличие описанной деривации, ни одно из значений не является главным, то есть отсутствует их иерархия 'It should be emphasized that although these meanings are presumably semantic derivates, there is no hierarchy among them' (Evteeva, 2014);

Нам же представляется, что именно сохранение и актуализация прототипического значения реализация поричи действия позволяет глаголам tип и dо использоваться в подобных конструкииях ... - 'It is the prototypical meaning of the verbs tun and do that appears to make these models acceptable ...' (Evteeva, 2014).

Impersonal structures Кажется / Представляется / Как представляется / Думается, что P ... ('It seems / It appears / I think that P ...') lack "self-mention" devices (person pronouns and possessive adjectives that convey propositional, affective and interpersonal information (Hyland, 2005)) while the logical subject (the author) is implied.

Consider examples that feature the absence of explicit author reference and the presence of implicit $\mathrm{Mbl}$ ('we'):

Отметим, что приоритетными сферами функционирования рассматриваемых лексических единиц являются мнемический монолог и мнемический нарратив - 'Notably, the words under consideration appear to be the most frequent in mnemonic monologues and mnemonic narratives' (Tivyaeva, 2018);

Заметим, что как прототипические значения, так и их инвариант характеризуются как гештальты - 'Notably, both prototypical and invariant meanings appear to be gestalts' (Evteeva, 2014).

First person plural pronoun $\mathrm{Mbl}$ ('we') and its forms ("reader pronouns") - mostly implicit in Russian academic discourse - bind the author and the reader, integrate these two parts of the communicative process via common context, shared concerns, boost the level of the text's interactivity, thus contributing to a more successful and productive dialogue between the participants.

The study revealed that both Russian academic texts demonstrate zero occurrences of personal pronoun $я$ (' $I$ ') and its forms (the only example found is the use of possessive pronoun мой ('my') in the author's notes like (Перевод мой. - И.Т.) ('translation by author') (Tivyaeva, 2018), (Здесь и далее перевод мой - M.E.) ('here and hereafter translation by author') (Evteeva, 2014)). The avoidance of specific reference to the author by eliminating the use of first person pronouns - that is so characteristic of Russian academic discourse - is generally a conscious choice by writers to disguise the author and to 
focus on factual information downplaying his / her "personal role to highlight the phenomena under study, the replicability of research activities, and the generality of the findings, subordinating their (writers') own voice to that of unmediated nature" (Hyland, 2005).

The analysis revealed two clusters of the most frequent linguistic representations of the category of subject (see Table 1): 1) parenthetical definite-personal clauses; 2) parenthetical impersonal clauses with modal words; 3) parenthetical subordinate impersonal clauses, and 4) parenthetical words / phrases.

The statements with epistemic devices - cf. можно, следует - help authors represent research findings and avoid straightforward communicating their attitude to the research results and expressing the preferred interpretation. Such boosting expressions as Надо полагать (lit. Must suppose-inf. - 'I think/ I guess'), Необходимо подчеркнуть ('It should be emphasized'), Нельзя не сказать о том, что ('It must be said that'), on the contrary, were not found in Text 2 and are quite rare in Text $2(0.006 \%)$.

Besides, the contrastive analysis of the texts resulted in certain differences between the authors' academic discourses (consider the total relative frequencies of parenthetical words and clauses employed in Text $1(0.137 \%)$ and Text $2(0.057 \%))$. The author of Text 1 relies on a much wider variety of boosting and hedging devices (Text 1 features 31 out of 54 structures analysed, while Text 2 employs 17). A most frequent expression На наш взгляд ('In our opinion') for Text $2(0.03 \%)$ features rare occurrence in Text $1(0.003 \%)$; the model expression Можно предположить ('Presumably') has an occurrence of $0.01 \%$ in Text 1 in comparison to its zero occurrence in Text 2.

\section{Conclusions}

Through working on the project students learn to work as a team, develop relevant research skills, master the DA's framework and techniques as well as oral presentation skills. The research findings consist in the revealed frequency of various linguistic representations of the category of subject, the means of its linguistic representation that prevail in the modern academic discourse, semantic and structural analyses of the data. We may conclude that integrating DA in project-based learning stimulates students and boosts their academic writing skills, empowering them with 1) the increased armoury of the resources employed by the authors of academic texts that helps avoid the risk of not establishing an academic dialogue with the reader, 2) understanding that the extent to which authors can reveal their identity varies and appears to be culture-/language-specific. The format proves to be a stimulating and beneficial experience as professional and linguistic competences may be better instilled through such projects than through writing a traditional individual term paper.

\section{References}

Alsoraihi, M. H. (2019). Bridging the Gap Between Discourse Analysis and Language Classroom Practice. English Language Teaching, 12(8), 79-88.

Carmo, M. (Ed.). (2018). Education and New Developments 2018. Lisboa: InScience Press.

Cots, J. M. (1996). Bringing Discourse Analysis into the Language Classroom. Links \& Letters, 3, 77-101.

Evteeva, M. Y. (2014). Modeling the semantic structure of verbs with a broad meaning "do / make" in the natural language (PhD Thesis). Moscow City University, Moscow.

Fomina, M. A. (2017). The addresser's markers in academic dialogue. Culturological approach to linguistics in the system of higher education, Vol. 1, 2(10), 96-103.

Hyland, K. (1994). Hedging in academic writing and EAP textbooks. English for Specific Purposes, 13(3), 239-256.

Hyland, K. (1999). Disciplinary Discourses: Writer Stance in Research Articles. In C. Candlin \& K. Hyland (Eds.), Writing: Texts: Processes and Practices (99-121). London: Longman.

Hyland, K. (2005). Stance and engagement: a model of interaction in academic discourse. Discourse Studies, 7(2), 173-192.

Hyland, K. (2009). Academic Discourse: English in a Global Context. London: Continuum.

Martínez, D. F. (2011). Introducing Discourse Analysis in Class. Newcastle upon Tyne: Cambridge Scholars Publishing.

Suleimanova, O. A., Yaremenko, V. I., \& Vodyanitskaya, A. A. (2018). Combining project-based learning and role play in synergetic teaching. ICERI2018 Proceedings, 10414-10419. doi:10.21125/iceri.2018.0964

Tivyaeva, I. V. (2018). Cognitive-communicative model of mnemonic processes (Doctoral Thesis). Moscow City University, Moscow. 